\title{
Roles of Genotype-Determined Mycotoxins in Maize Seedling Blight Caused by Fusarium graminearum
}

Yan Meng, Department of Plant Pathology, China Agricultural University/Key Laboratory of Plant Pathology, Ministry of Agriculture, China Agricultural University, Beijing 100193, P. R. China; Department of Plant Pathology and Microbiology, Iowa State University, Ames, 50011; and College of Agriculture and Biotechnology, Hexi University, Zhangye, 734000, P. R. China; Jianjun Hao, School of Food and Agriculture, The University of Maine, Orono, 04469; Derrick Mayfield, Department of Plant Pathology and Microbiology, Iowa State University, Ames, 50011; Laixin Luo, Department of Plant Pathology, China Agricultural University/Key Laboratory of Plant Pathology, Ministry of Agriculture, China Agricultural University, Beijing 100193, P. R. China; Gary P. Munkvold, Department of Plant Pathology and Microbiology, Iowa State University, Ames, 50011; and Jianqiang Li, Department of Plant Pathology, China Agricultural University/Key Laboratory of Plant Pathology, Ministry of Agriculture, China Agricultural University, Beijing 100193, P. R. China

\begin{abstract}
Fusarium graminearum is an important causal agent of maize seedling blight. The species includes several chemotypes that produce various forms of deoxynivalenol (DON) and nivalenol (NIV). To understand the effects and roles of $F$. graminearum mycotoxins on maize seedling blight occurring at Zhang Ye of Gansu, China, 23 isolates of $F$. graminearum were collected and characterized. A PCR assay showed all 23 isolates belonged to the 15-acetyldeoxynivalenol (15-ADON) genotype. This was also confirmed by production of both DON and 15-ADON in either rice culture medium or maize seedling roots, detected by high performance liquid chromatography and mass spectrometry. In maize seedling roots, 15-ADON dominated at 6 days post inoculation (dpi) and DON was the main mycotoxin at $12 \mathrm{dpi}$. The biomass of $F$. graminearum doubled from 6 to $12 \mathrm{dpi}$, and was positively correlated with virulence of the isolates. Both mycotoxins affected maize root vitality, but $15-\mathrm{ADON}$ had a greater effect than DON. $A L D H 9$

and $M D H$, two dehydrogenase synthesis genes in maize, showed a lower relative expression in $15-\mathrm{ADON}$ treatments than in DON treatments. It indicated that both mycotoxins affected seed germination and root development, with 15 -ADON being more destructive. Under scanning electron microscopy and transmission electron microscopy, root hair formation and development were delayed by DON, but completely inhibited by $15-A D O N$. 15-ADON caused cell shrinkage, loose cellular structure, and widened intercellular spaces; it also destroyed organelles and caused plasmolysis, and eventually ruptured cell membranes causing cell death. DON did not affect cell morphology and arrangement, but altered the morphology of organelles, forming concentric membranous bodies and a large amount of irregular lipid droplets. Thus, both mycotoxins contributed to symptom expression of maize seedling blight, but $15-\mathrm{ADON}$ was more destructive than DON.
\end{abstract}

Maize seedling blight (MSB) is an important disease in maize growing regions in China (Guan et al. 1994; Wang et al. 1992, 2012; Zhao and Ren 2003), and its occurrence has increased rapidly in recent years (Lei and Chen 2006; Xin et al. 2010). Zhangye, located in the Hexi Corridor of Gansu Province, is the largest area of maize seed production in China, where 50\% of 900,000 tons of hybrid seed are produced. MSB has been a common disease that causes significant yield losses in Hexi Corridor. Fusarium graminearum, which can be both seed-borne and soil-borne, is a major pathogen causing MSB (du Toit et al. 1997; Kingsland and Wernham 1960; Munkvold and O'Mara 2002; Obanor and Chakraborty 2014; Zhao and Ren 2003). Our preliminary study suggested $F$. graminearum is the main pathogen causing MSB in Zhangye of Gansu Province (Y. Meng et al., unpublished data).

In addition to causing significant yield losses, $F$. graminearum can produce type B trichothecene mycotoxins such as nivalenol (NIV), deoxynivalenol (DON), and their acetylated derivatives that contaminate kernels and make grain unsafe for human and livestock consumption (Liang et al. 2014; Quarta et al. 2006). Chemotypes of the pathogen are defined based on type B trichotechene production (Quarta et al. 2006). The nivalenol chemotype produces NIV and 4-acetylnivalenol (4A-NIV), the 3-ADON chemotype produces DON and 3-acetyldeoxynivalenol (3-ADON), and the 15-ADON chemotype produces DON and 15-acetyldeoxynivalenol (15-ADON) (Liang et al. 2014; Quarta et al. 2005, 2006; Reynoso et al. 2011). Mycotoxin

Corresponding authors: Jianqiang Li, E-mail: lijq231@cau.edu.cn; Gary P. Munkvold, E-mail: munkvold@ iastate.edu

Accepted for publication 16 March 2017.

() 2017 The American Phytopathological Society chemotypes highly correlate with sensitivity to some fungicides, such as carbendazim, tebuconazole, and epoxiconazole. NIV-producing strains were significantly more resistant to tebuconazole and epoxiconazole than DON-producing strains (Hellin et al. 2016). Most $F$. graminearum strains that produce either NIV or 15-ADON are sensitive, but the 3-ADON producers are resistant to carbendazim (Audenaert et al. 2010; L. Zhang et al. 2013). F. graminearum can move from inoculated stem bases to flag-leaf nodes, mature heads, and even kernels of wheat (Mudge et al. 2006). Furthermore, it can effectively colonize at the crown without showing symptoms (Covarelli et al. 2012; Winter et al. 2013), which is presumably the result of host defense responses (Stephens et al. 2008). Meanwhile, DON is produced and accumulates in grains (Mudge et al. 2006). Therefore, if the pathogen behaves similarly in maize, $F$. graminearum and mycotoxins may be translocated to maize ears and contaminate grain during plant development if maize seedlings survive MSB. That said, understanding the chemotype composition of $F$. graminearum populations is important to guide the use of fungicides, to predict toxin production, and to evaluate the risk posed by contaminated food or feed.

Although type B trichothecenes differ only slightly in structure from each other in terms of the pattern of hydroxylation or acetylation, these differences can greatly affect the toxicity of these compounds (Kimura et al. 1998). DON is associated with feed refusal, vomiting, and suppressed immune functions, and NIV is more toxic to humans and domestic animals than DON (Liang et al. 2014; Oliveira et al. 2012; Reynoso et al. 2011). Trichothecenes are also potent phytotoxins (Desjardins 2006). DON inhibits eukaryotic protein synthesis, damages plasma membranes, chloroplasts, and ribosomes (Bushnell et al. 2005; Eudes et al. 2000; Miller et al. 1997), and also triggers hydrogen peroxide production and causes cell death in cereals (Walter et al. 2010). A majority of research has focused on Fusarium head blight of small grains and DON production; DON studies were based on the mutants of Tri genes, such as Tri4, Tri5, and Tri6 (Audenaert 
et al. 2013; Walter et al. 2010), which encode key synthases of trichodiene in the trichothecene pathway. These mutants were not only DON-nonproducers but also 15-ADON-nonproducers. Little is known about the presence and role of mycotoxins in early maize seedling infection. The wild type of $F$. graminearum caused greater effects on maize stalk, roots, and mesocotyl than nonproducing mutants (Bruns 2015; Quesada-Ocampo et al. 2016), and the biomass in maize tissue inoculated by wild types also showed a higher colonization than mutants (Bruns 2015). This study aimed to assay genotype and chemotype of $F$. graminearum isolates from MSB samples, analyze trichothecene production in vitro and in planta, and compare the effects of different mycotoxins on root development.

\section{Materials and Methods}

Pathogen isolation and DNA extraction. F. graminearum isolates were collected in April 2013, from Ganzhou and Linze counties of Zhangye, which represent the major maize production area of the Hexi Corridor. Symptomatic maize seedlings at growth stage V1 were collected, and the root pieces were sterilized, placed on potato dextrose agar (PDA), and incubated at $25^{\circ} \mathrm{C}$ for 2 days in the dark. Mycelia growing from the root pieces were transferred to a new PDA plate, and each culture was purified by single spore isolation method. To extract genomic DNA, $F$. graminearum cultures were grown in potato dextrose broth and incubated on an orbital shaker at $120 \mathrm{rpm}$ for 4 days at $25^{\circ} \mathrm{C}$. The medium was removed by centrifugation and the mycelia were stored at $-80^{\circ} \mathrm{C}$ for later use. Approximately one gram of harvested mycelium was ground in liquid nitrogen into a very fine powder, and DNA was extracted using a cetyltrimethyl ammnonium bromide (CTAB) method (Arif et al. 2011).

Molecular determination of genotypes. The genotypes were determined using PCR. Primer set 3551 (5'-ACTTTCCCACCGAG TATTTT-3')/4056 (5'-CAAAAACTGTTGTTCCACTGCC-3') based on Tri5 gene sequence was used for the identification of DONproducing chemotypes (Quarta et al. 2005). Primer sets Tri3F971 (5'-C ATCATACTCGCTCTGCTG-3')/Tri3R1679 (5'-TT(AG)TAGTTTG CATCATT(AG)TAG-3') and Tri3F1325 (5'-GCATTGGCTAACAC ATGA-3')/Tri3R1679 were used to identify the 15-ADON and 3-ADON chemotypes, respectively, whereas the primer set Tri7F340 (5'-ATCGTGTACAAGGTTTACG-3')/Tri7R965 (5'-TTCAAGTAA CGTTCGACAAT-3') identified the NIV chemotype (Quarta et al. 2006). Using the selected primers, specific amplification products of 625, 354, and 708 bp were obtained from NIV, 3-ADON, and 15-ADON, respectively (Quarta et al. 2006). PCR assays were carried out using 10 to $20 \mathrm{ng}$ of DNA in a total volume of $25 \mu \mathrm{l}$ containing $10 \times$ reaction buffer, $0.5 \mu \mathrm{M}$ of each primer, $200 \mu \mathrm{M}$ of each dNTP, and $1.25 \mathrm{U}$ of Taq DNA polymerase. Thermal cycler settings were as follows: predenaturation at $95^{\circ} \mathrm{C}$ for $1 \mathrm{~min}$, followed by 35 cycles of denaturation at $94^{\circ} \mathrm{C}$ for $30 \mathrm{~s}$, annealing at $56^{\circ} \mathrm{C}$ for $30 \mathrm{~s}$ and elongation at $72^{\circ} \mathrm{C}$ for $60 \mathrm{~s}$, and a final elongation at $72^{\circ} \mathrm{C}$ for 10 min; a negative control without DNA template was performed. PCR amplicons were sequenced from both directions by Biomed Company (Beijing, China). The DNA sequences were aligned and edited by removing the low quality bases on both ends using Bioedit software (Ibis Biosciences, U.S.A.). The sequences were analyzed to identify the isolates using the BLAST algorithm against the NCBI database (https://blast.ncbi.nlm.nih.gov/Blast.cgi). All the sequences were uploaded to GenBank with accession numbers KY496221-43.

Fungal growth on rice medium. F. graminearum cultures were grown as previously described with minor changes (Reynoso et al. 2011). All 23 F. graminearum isolates were cultured in Erlenmeyer flasks $(250 \mathrm{ml})$ containing rice medium $(10 \mathrm{~g}$ of rice and $100 \mathrm{ml}$ of distilled water). Agar disks ( $6 \mathrm{~mm}$ diameter) were taken from the margins of actively growing colonies on PDA after 4 days at $25^{\circ} \mathrm{C}$. Ten disks were transferred into a flask and incubated for 20 days on an orbital shaker at $120 \mathrm{rpm}$ and $25^{\circ} \mathrm{C}$ in the dark. After incubation, the contents of the flask were dried at $50^{\circ} \mathrm{C}$ for $24 \mathrm{~h}$ and ground to powder, then stored at $-20^{\circ} \mathrm{C}$ until use. This experiment was conducted three times with three replications.

Chemotype analysis by HPLC-MS. Mycotoxin standards of NIV, DON, 3-ADON, and 15-ADON were supplied by Sigma
Aldrich Chemical Co. (St. Louis, MO, U.S.A.). Acetonitrile and methanol were purchased from Thermo Fisher Scientific, Co., Ltd (China). All standards were dissolved in methanol at a concentration of $1.0 \mathrm{mg} \mathrm{ml}^{-1}$ and stored at $4{ }^{\circ} \mathrm{C}$ in a sealed vial until use. Working standards $\left(10.0,5.0,1.0,0.5,0.1\right.$, and $\left.0.05 \mu \mathrm{g} \mathrm{ml}^{-1}\right)$ were prepared by appropriate dilution of the stock solution with methanol and used to obtain calibration curves in the appropriate chromatographic system. Sample preparation was performed by the method of Quarta et al. (2005).

HPLC-MS analysis was performed following the method of $\mathrm{Xu}$ (Xu et al. 2014) with minor modification. An Agilent 1100 Series LC/MSD Trap SL (Agilent Technologies, Waldbronn, Germany) equipped with an Agilent XDB C18 $(150 \mathrm{~mm} \times 4.6 \mathrm{~mm}, 5 \mu \mathrm{m}) \mathrm{col}-$ umn was used for the chromatographic separation of the trichothecenes. The UV detector was set at $220 \mathrm{~nm}$ and the injection volume was $20 \mu \mathrm{l}$. The mobile phase was composed of acetonitrile (A) and $0.1 \%$ formic acid in water (B). A binary gradient at a flow rate of $1.0 \mathrm{ml} / \mathrm{min}$ was performed as follows: 0 to $3 \mathrm{~min} 30 \% \mathrm{~A}, 4$ to $6 \mathrm{~min}$ $50 \%$ A, 7 to 10 min $65 \%$ A, 11 to $15 \min 10 \%$ A (Xu et al. 2014). Mycotoxins were identified by using the multiple-reaction monitoring mode (MRM) in positive ionization mode. The source temperature was $350^{\circ} \mathrm{C}$, and the capillary voltage was set at $110.3 \mathrm{~V}$. The curtain gas was at $35 \mathrm{psi}$, and the ion source gas (nebulizer) was at $60 \mathrm{psi}$.

Inoculation and trichothecene analysis in maize roots. Based on bioassay results (Y. Meng et al., unpublished data), F. graminearum isolates were divided into three groups by virulence levels: high, intermediate, and low virulent groups. Six isolates of $F$. graminearum representing different levels of virulence (two high virulence, two intermediate, and two low virulence) were chosen for inoculation. $F$. graminearum isolates were cultured on synthetic nutrient agar (SNA) at $25^{\circ} \mathrm{C}$ for 14 days; spores were collected by flushing the culture three times with sterile distilled water and collecting the singes of conidia. The spore suspension was calibrated to $10^{5} \mathrm{cfu} \mathrm{ml}^{-1}$ with the aid of a hemocytometer. The medial resistant maize hybrid Jingke968 was used for inoculation. Four maize seeds were planted in a $200-\mathrm{ml}$ container containing $80 \mathrm{~g}$ sterile potting soil and $5 \mathrm{ml}$ of $10^{5} \mathrm{ml}^{-1}$ conidial suspension. Each treatment had three replicates. Seedlings were harvested at 6 and 12 days post inoculation (dpi) for mycotoxin quantification and measurement of fungal biomass. Roots were rinsed thoroughly and frozen at $-20^{\circ} \mathrm{C}$ until analysis. The experiment was conducted three times.

Detection of $F$. graminearum biomass in infected maize roots by a quantitative real-time PCR. Maize seedling roots were harvested at 6 and 12 dpi for measurement of $F$. graminearum biomass in root tissue. A total of $300 \mathrm{mg}$ of roots was ground into powder with a Geno grinder (SPEX CertiPrep Inc., Metuchen, NJ, U.S.A.). DNA was extracted with the DNeasy Plant Mini Kit (QIAGEN, Hilden, Germany) according to the manufacturer's protocol. The concentration and quality of genomic DNA were examined using a Nano Drop 1000 spectrophotometer (Thermo Scientific, Wilmington, DE, U.S.A.). Serial dilutions of $F$. graminearum DNA were used to create a standard curve for a Taq Man MGB (minor groove binder) assay.

The primer set and probe were designed to amplify the translation elongation factor 1-alpha $(E F 1)$ gene of $F$. graminearum; the probe was labeled with FAM and contained TAMRA as quencher. Their sequences are as follows: MGB-F: 5'-GGCGCTTCTCGTGAACAC A-3', MGB-R: 5'-TGGCTAAACAGCACGAATGC-3', MGB probe: 5'-AGATATGTCTCTTCAAGTCT-3'. All reactions were performed in a total volume of $20 \mu \mathrm{l}$ using 96-well microwell plates in an ABI Fast 7500 apparatus; each PCR reaction contained $10 \mu \mathrm{l}$ TaqMan Gene Expression Master Mix (ABI), $2.5 \mu \mathrm{M}$ of probe, forward and reverse primer, $1 \mu \mathrm{l}$ template DNA, and $2 \mu \mathrm{l}$ water. The cycling conditions consisted of a single cycle of $2 \mathrm{~min}$ at $50^{\circ} \mathrm{C}$ and $10 \mathrm{~min}$ at $95^{\circ} \mathrm{C}$, followed by 40 cycles of $95^{\circ} \mathrm{C}$ for $15 \mathrm{~s}$ and $60^{\circ} \mathrm{C}$ for $1 \mathrm{~min}$. Triplicates were used for each sample. Negative control was included by replacing the DNA template with sterile water.

Effects of DON and 15-ADON on seed germination. Twenty maize seeds soaked in $10 \mathrm{ml}$ of $20 \mu \mathrm{g} \mathrm{ml}^{-1}$ DON or 15-ADON for $12 \mathrm{~h}$ were germinated by rolled paper method. Daily germination was recorded until the seventh day after incubation. Root length 
and fresh plant weight were measured. Seeds soaked in water were used as the control. Each treatment had three replicates. Germination rate, germination index, and vigor index of seeds were calculated as follows:

$$
\begin{gathered}
\text { Germination rate }=100 \times \text { number of germinated seeds } / \\
\text { total number of planted seeds }
\end{gathered}
$$

$$
\text { Germination index }=\left(\sum \mathrm{Ti} \cdot \mathrm{Ni}\right) / \mathrm{S}
$$

where $\mathrm{Ti}$ is the number of days after planting, $\mathrm{Ni}$ is the number of seeds germinated on day I, and S is the total number of planted seeds.

$$
\text { Vigor index }=\mathrm{S} \times \sum(\mathrm{Gt} / \mathrm{Di})
$$

where $S$ is seedling height of the seventh day, Gt is the number of germinated seeds on day I, and Di is the number of days from the first day to I day.

Effects of DON and 15-ADON on maize root vitality. The vitality of maize roots treated by mycotoxins was estimated by the triphenyltetrazolium chloride (TTC) method. TTC added to root tissue can be reduced by enzymes, mainly dehydrogenases, and thereby provides an estimate of dehydrogenase vitality (Clemensson-Lindell 1994). Sterilized maize seeds were germinated by rolled paper method until root length reached $3 \mathrm{~cm}$. Ten of these seeds were soaked in $20 \mathrm{ml}$ of $20 \mu \mathrm{g} \mathrm{ml}^{-1}$ DON or 15 -ADON. Roots were sampled every $12 \mathrm{~h}$ until $96 \mathrm{~h}$ and root vitality was tested by the TTC method (Islam et al. 2007). The root vitality was expressed by the mount of TPF (triphenyl formazan) deoxidized by TTC. Each treatment had three replications. The experiment was conducted three times.

Effects of DON and 15-ADON on $A L D H 9$ and $M D H$ in maize roots. The roots treated with $20 \mu \mathrm{g} \mathrm{ml}^{-1}$ of either DON or $15-\mathrm{ADON}$ were used to test the relative expression of two dehydrogenases, aldehyde dehydrogenase $(A L D H 9)$ and malate dehydrogenase $(M D H)$. Roots $(100 \mathrm{mg})$ were immediately frozen in liquid nitrogen after sampling and ground using a Geno Grinder. Total RNA was extracted using a SV total RNA isolation system (Promega Corp, Madison, WI, U.S.A.) following the manufacturer's instructions. The quality of the RNA was examined by agarose gel electrophoresis and the RNA concentration was measured using a Nanodrop 1000 spectrophotometer. Total RNA was reverse-transcribed using the PrimeScript RT reagent kit (Takara, Dalian, China). cDNA samples were stored at $-80^{\circ} \mathrm{C}$ for real-time PCR analysis. Abundance of the transcripts of $A L D H 9$ and $M D H$ was evaluated using the ABI Fast7500 apparatus and ABI 7500 Software, with $1 \mathrm{ml}$ of diluted cDNA in a 20-ml PCR reaction, using the SYBR Premix DimerEraser kit (Takara Bio Inc, Dalian, China) according to the manufacturer's instructions. Expression of GAPDH was used as endogenous control. PCR reactions were carried out at $95^{\circ} \mathrm{C}$ for $30 \mathrm{~s}$, followed by 40 cycles of $95^{\circ} \mathrm{C}$ for $30 \mathrm{~s}, 55^{\circ} \mathrm{C}$ for $30 \mathrm{~s}$, and $72^{\circ} \mathrm{C}$ for $30 \mathrm{~s}$. Primer pairs for amplifying the genes were as follows: GAPDH-f1: 5'-CTGGTTTCTACCGACTTCCTTG-3', GAPDH-r1: 5'-CGGCATACACAAGCAGCAAC-3' (Gu et al. 2010); ALDH9-f: 5'-CATCTACGTGCAGGAAGGGAT-3', ALDH9-r: 5'TTGGCTGACACTCGGGTTG-3' (Zhou et al. 2012); MDH-f: 5'GGAAGGAGGGAATGGAAAGG-3', MDH-r: 5'-ACGGGTCAGG CAAGTAAC-3' (Menckhoff et al. 2013). Each treatment had three replicates. Real-time PCR data were analyzed using the $2^{-\Delta \Delta \mathrm{Ct}}$ method (Livak and Schmittgen 2001).

Effects of DON and 15-ADON on root development. Maize seedling roots were treated with $20 \mu \mathrm{g} \mathrm{ml}^{-1}$ DON and 15-ADON for $24,48,72$, and $96 \mathrm{~h}$, and the ultrastructure of root tip development (including maturation zone, elongation zone, and root tips) was observed under scanning electron microscopy (SEM) and transmission electron microscope (TEM). The samples were fixed with $2.5 \%(\mathrm{v} / \mathrm{v})$ glutaraldehyde for $2 \mathrm{~h}$, followed by rinsing three times with $50 \mathrm{mM}$ phosphate buffer ( $\mathrm{pH}$ 7.2). The specimens were then fixed in $1 \%(\mathrm{w} / \mathrm{v})$ osmium tetroxide for $2 \mathrm{~h}$, and rinsed with $50 \mathrm{mM}$ phosphate buffer. The samples for SEM observation were dehydrated in an ethanol gradient series, critical-point dried, and sputter coated with gold-palladium. Samples were viewed using a HITACHI S-3400 N scanning electron microscope
(Hitachi, Japan) operating at $15 \mathrm{k}$. The samples for TEM observation were dehydrated in a gradient acetone series and embedded in Spurr epoxy resin. Thin $(2 \mu \mathrm{m})$ sections were obtained with a Leica UC6 ultratome (Leica, Austria) and stained in uranyl acetate and lead citrate. Samples were viewed with a JEM-1230 transmission electron microscope (JEOL, Tokyo, Japan).

Data analysis. Data Processing System ver. 9.5 (Zhejiang University, Hangzhou, China) was used for data analysis. Analysis of variance (ANOVA) for a general linear model was used to evaluate treatment effects. Mean separation was performed using Tukey's multiple range test at significance level of 0.05 for germination, vigor, root vitality, and mycotoxin concentration. Regression was used to determine the correlation between disease index and mycotoxin or between disease index and $F$. graminearum biomass.

\section{Results}

Genotype determination of $\boldsymbol{F}$. graminearum. Two PCR products, with sizes of 525 and $708 \mathrm{bp}$, respectively, were observed after amplification of $F$. graminearum DNA by using primer pairs $3551 \mathrm{H} /$ $4056 \mathrm{H}$ and tri3f971/tri3R1679, respectively, but no production was found when primers tri3f1325/tri3R1679 and Tri7F340/Tri7R965 were used. Therefore, all of the $F$. graminearum isolates belonged to $15-\mathrm{ADON}$ genotype according to the results of Quarta et al. (2006). Sequence analysis of the 525-bp product had $99 \%$ similarity to trichodiene synthetase (Tri5) gene (AF508152.1); the 708-bp product had $99 \%$ similarity to Tri3 (AY102597.1) with translation product of 15-O-acetyltransferase. All results had identity similarity $\geq 99 \%$ and $\mathrm{E}$ value $=0$.

Trichothecene analysis on rice medium and in maize roots. Among the $23 F$. graminearum isolates grown on rice medium, neither NIV nor 3-ADON was detected by HPLC-MS, but both DON (up to $30 \mu \mathrm{g} \mathrm{g}^{-1}$ ) and $15-\mathrm{ADON}$ (up to $180 \mu \mathrm{g} \mathrm{g}^{-1}$ ) were detected in the cultures. Only the 15 -ADON chemotype was confirmed in all the $F$. graminearum isolates. However, there was no correlation between the production of both mycotoxins in vitro and the virulence of $F$. graminearum (Fig. 1).

Both DON and 15-ADON were discovered in all maize samples. $15-A D O N$ was the dominant mycotoxin at $6 \mathrm{dpi}$ and the content was positively correlated with virulence $\left(r^{2}=0.72, P=0.05\right)$. Although DON was detected in maize roots at $6 \mathrm{dpi}$, it showed a much lower concentration $(\leq 0.01 \mu \mathrm{g} / \mathrm{g})$ compared with 15 -ADON (Fig. 2A). DON increased sharply at $12 \mathrm{dpi}$ and the content was positively correlated $\left(r^{2}=0.77, P=0.01\right)$ with the virulence of $F$. graminearum. Meanwhile, 15-ADON increased in seedlings infected with weakly virulent isolates but decreased in seedlings infected with medium and highly virulent isolates (Fig. 2B).

$F$. graminearum biomass in infected maize roots. $F$. graminearum biomass in maize seedling roots doubled from 6 to 12 dpi. Biomass was positively correlated with strains' virulence at $6 \mathrm{dpi}$ $\left(r^{2}=0.69, P=0.05\right)$ and $12 \mathrm{dpi}\left(r^{2}=0.67, P=0.05\right)$, respectively. Maize roots infected by highly virulent isolates contained higher biomass $F$. graminearum than with isolates with low or intermediate virulence at both 6 and 12 dpi (Fig. 3). There was no significant difference of biomass contents between low and intermediately virulent isolates in most samples $(P>0.05)$.

Effect of DON and 15-ADON on seed germination and root vitality of maize seedling. Germination rate, germination index, and vigor index of maize were decreased by DON and 15-ADON treatments. ANOVA indicated there was no significant difference between the effects of DON and 15-ADON $(P=0.12,0.44,0.51) .15-\mathrm{ADON}$ showed a greater impact on root length than DON (Figs. 4 and 5, $P=0.007)$. DON and $15-\mathrm{ADON}$ decreased root vitality in all testtime points; the effects were negatively correlated with treating time, starting from $60 \mathrm{~h}\left(r^{2}=0.96, P=0.05 ; r^{2}=0.94, P=0.05\right)$. Maize roots treated with $15-\mathrm{ADON}$ showed a lower root vitality compared with those treated by DON (Fig. 6).

Effects of DON and 15-ADON on the expression of $A L D H$ and $M D H$ genes in maize. $A L D H$ and $M D H$ expression in maize seedling roots was affected by both DON and 15-ADON. ALDH and $M D H$ showed a lower relative expression in maize roots treated by $15-\mathrm{ADON}$ 
than by DON. For DON treatments, $A L D H$ expression increased three times higher than control at $24 \mathrm{~h}$, then decreased to the similar level of control at $48 \mathrm{~h} ; \mathrm{MDH}$ expression was upregulated to triple of control at $12 \mathrm{~h}$ and down to 1.3 times at $24 \mathrm{~h}$, then downregulated slightly at 72 and $96 \mathrm{~h}$. For $15-\mathrm{ADON}$ treatment, both genes showed a downregulated expression in all samples of five time points (Fig. 7).

Effects of DON and 15-ADON on root hair development. Toxins affected root hair development in the root maturation zone; they were sparser than the control when treated with DON for 24 and $48 \mathrm{~h}$, but no significant differences were observed at $72 \mathrm{~h}$, indicating the root hair development was delayed but not suppressed. For $15-\mathrm{ADON}$ treatment, root hairs were completely inhibited at all times and these plants developed few root hairs at $72 \mathrm{~h}$ (Fig. 8). None of the treatments affected elongation zone, arrangement, structure, or size of cells.

Effects of DON and 15-ADON on root tip development. SEM observation showed that both DON and 15-ADON affected the development of root tip cells. In the DON treatment, cell shape and arrangement did not change before $72 \mathrm{~h}$, but wrinkled cell walls were found at $96 \mathrm{~h}$; in $15-\mathrm{ADON}$ treatments, the destructive effect was

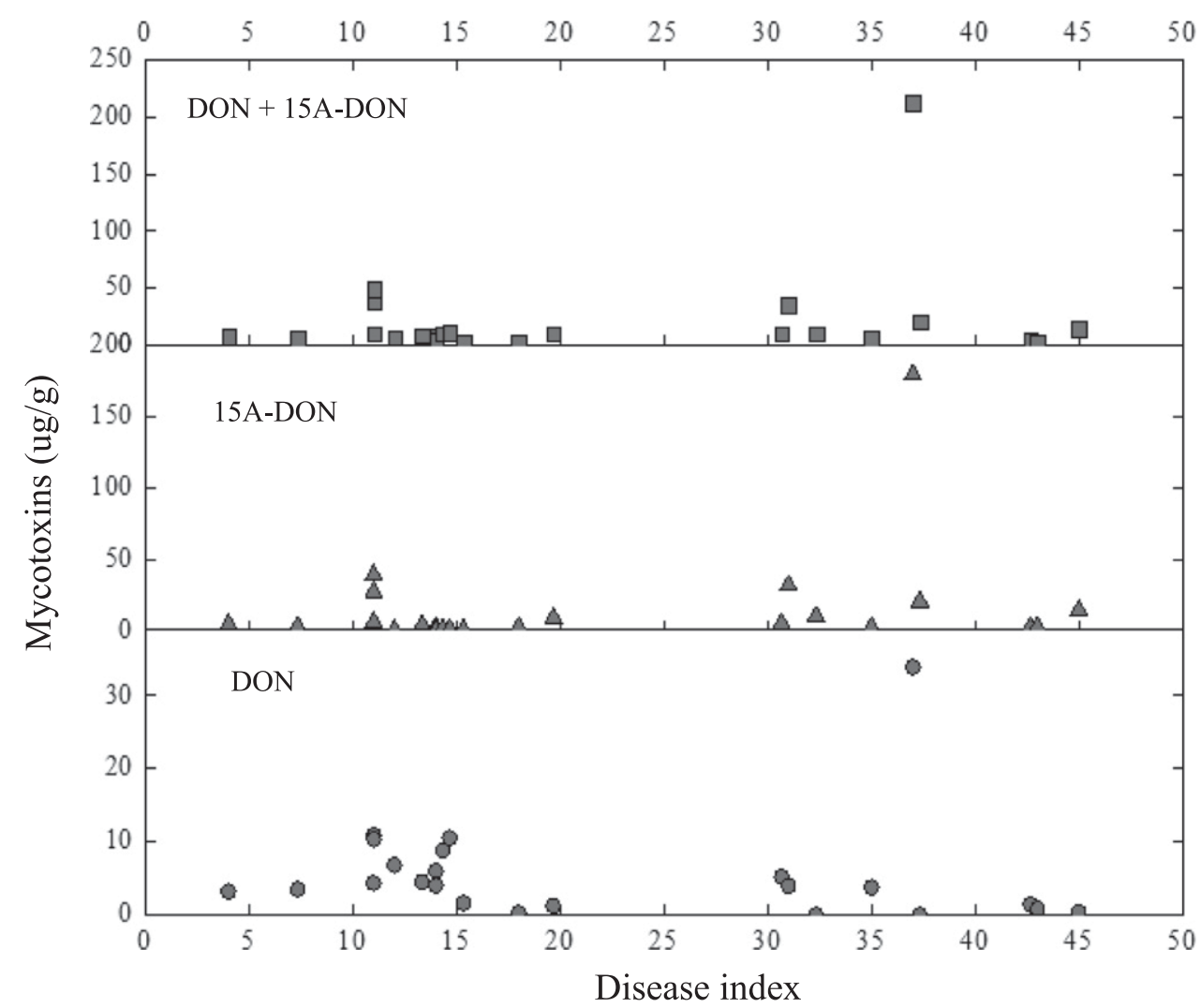

Fig. 1. Production of deoxynivalenol (DON) and 15-acetyl-deoxynivalenol (15-ADON) mycotoxins in Fusarium graminearum cultures. Circles, triangles, and squares represent DON, 15-ADON, and sum of DON and 15-ADON, respectively. Disease index was calculated based on percentage of diseased root length.

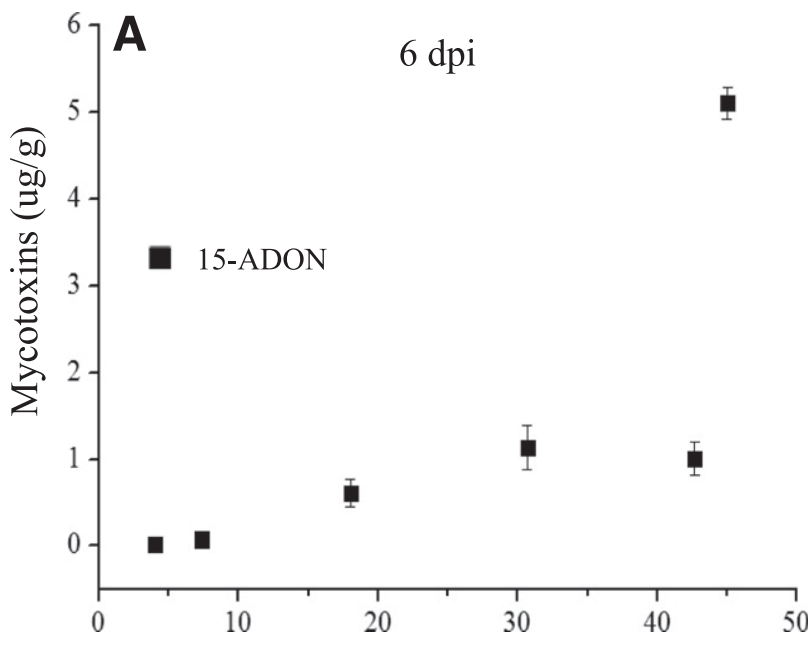

Disease index

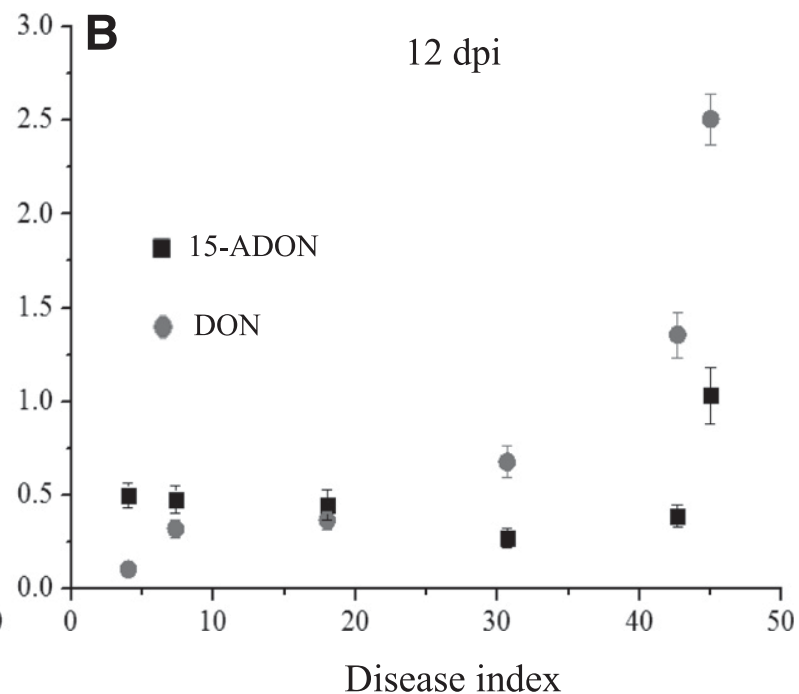

Disease index

Fig. 2. 15-acetyl-deoxynivalenol (15-ADON) and deoxynivalenol (DON) content in the roots of experimental maize seedling 6 days (A) and 12 days (B) post inoculation (dpi) with Fusarium graminearum. In regression analysis between mycotoxin (15-ADON or DON) and virulence, $r^{2}=0.72(P=0.05)$ at $6 \mathrm{dpi}$ and $r^{2}=0.77(P=0.05)$ at $12 \mathrm{dpi}$, respectively. 


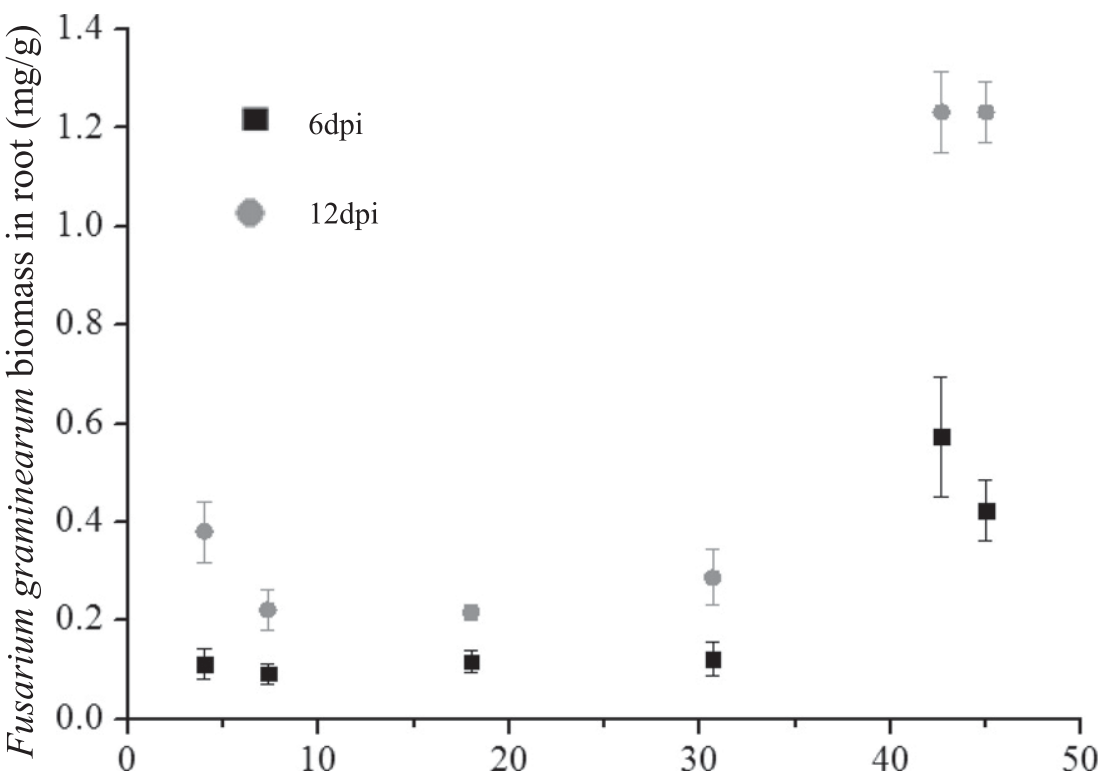

Disease index

Fig. 3. Biomass of Fusarium graminearum in the root of experimental maize seedling at 6 and 12 days post inoculation (dpi). In regression analysis between biomass and virulence, $r^{2}=0.69(P=0.05)$ at 6 dpi and $r^{2}=0.67(P=0.05)$, respectively.

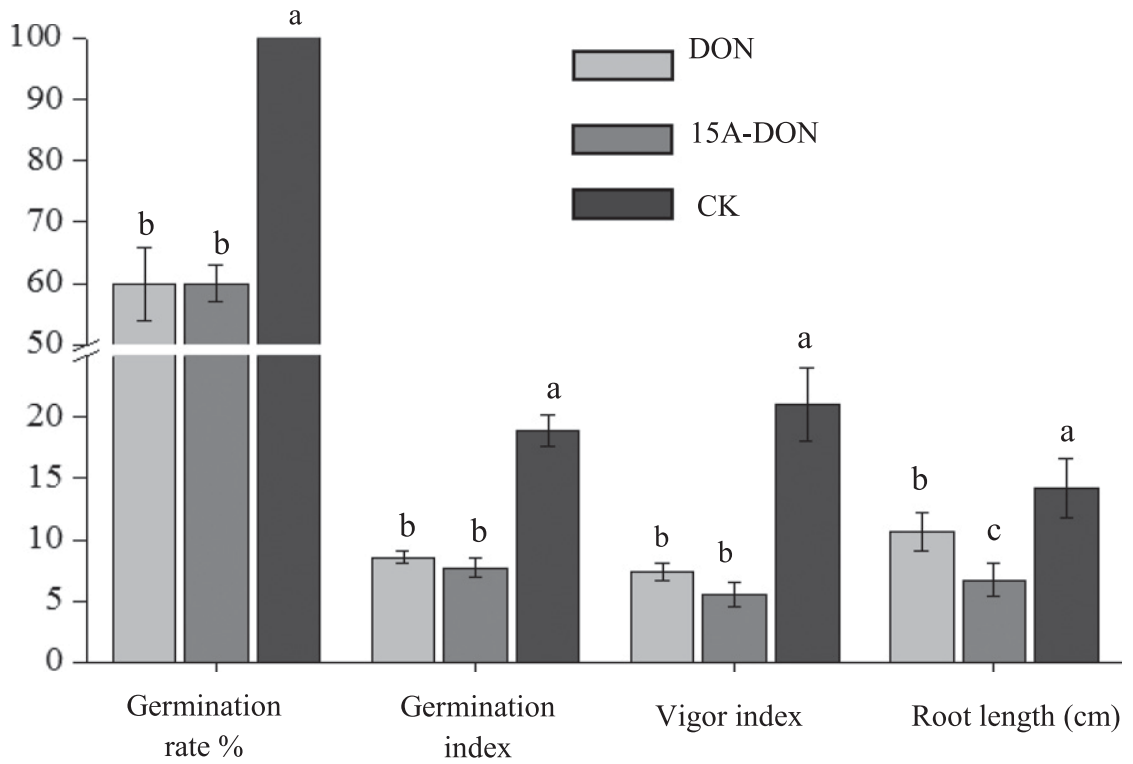

Fig. 4. Effect of deoxynivalenol (DON) and 15-acetyl-deoxynivalenol (15-ADON) on maize seed germination and root length. Seeds soaked in water were used as the control. Means values followed by the same letters in category (germination rate, germination index, vigor index, and root length) are not significantly different $(P>0.05)$.

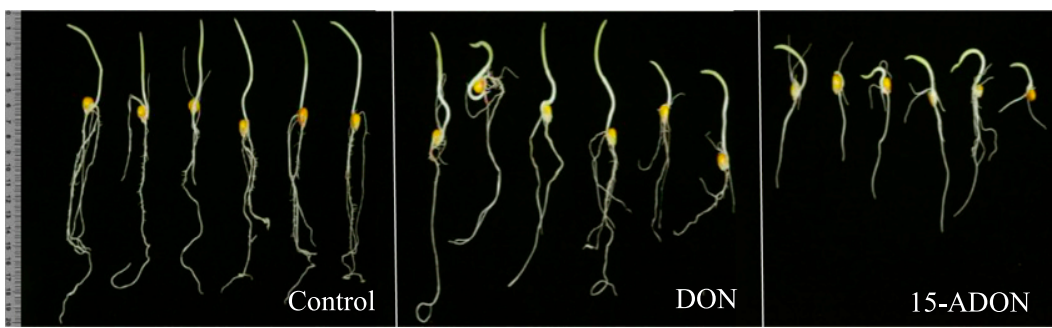

Fig. 5. Effect of deoxynivalenol (DON) and 15-acetyl-deoxynivalenol (15-ADON) on maize root length. 
significant after $48 \mathrm{~h}$, and shrunken cells, loose cellular structure, and widened intercellular spaces were observed at 72 and $96 \mathrm{~h}$ (Fig. 9).

TEM observation showed that DON did not alter the cell structure. Cell walls and organelles were intact after $96 \mathrm{~h}$. While few Golgi apparatus were observed and multilamellated structures of endoplasmic reticulum (concentric membranous bodies) were found in more than $40 \%$ of cells in the $24 \mathrm{~h} \mathrm{DON}$ treatment (Fig. 10). Most of these concentric membranous bodies were closed, and cytoplasmic components such as ribosomes, polysomic, lipid, and mitochondria could be enclosed in concentric membranous bodies (Okiyoneda et al. 2004). Broken concentric membranous bodies were observed at 48 $\mathrm{h}$, then broke into small multilevel parallel endoplasmic reticulum segments at $72 \mathrm{~h}$ and changed to normal endoplasmic reticulum at $96 \mathrm{~h}$ (Fig. 10). The other organelles such as mitochondria and Golgi apparatus were observed and did not exhibit alterations compared with the control. TEM observation also showed a larger amount of lipid droplets were produced in $24 \mathrm{~h}$ DON treatments compared with the control. The number of lipid droplets decreased with the treating time but some of them showed abnormal shapes (Fig. 11).

The effect of 15-ADON treatment varied depending on the cell organelles and time of treatment. The treatment took effect after $24 \mathrm{~h}$.

Very small amounts of endoplasmic reticulum and lipid droplets were observed at $48 \mathrm{~h}$, and some organelles were degraded appearing with a fuzzy shape. Plasmolysis was observed in most cells at $72 \mathrm{~h}$, and all cell organelles were degraded without intact structure. Cytomembranes were broken at $96 \mathrm{~h}$, resulting in cell damage (Fig. 10). Thus, DON affected the function of cell organelles by changing their number and shape, but 15-ADON destroyed cell organelles and killed cells directly.

\section{Discussion}

It is reported that the toxigenic potential of Fusarium spp. varies depending on geographic locations. NIV strains of Fusarium spp. used to be dominant but are being replaced by DON strains in China,

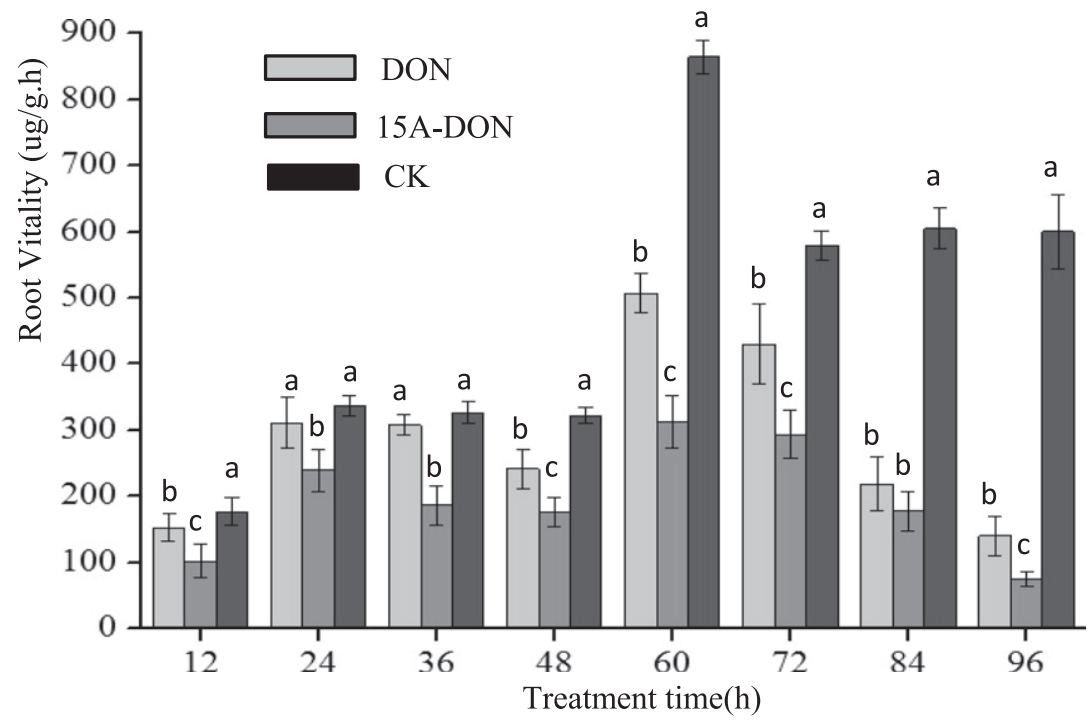

Fig. 6. Effect of deoxynivalenol (DON) and 15-acetyl-deoxynivalenol (15-ADON) on root vitality of maize. Root vitality was expressed by the amount of triphenyl formazan (TPF) deoxidized by triphenyltetrazolium chloride (TTC). Means values followed by the same letters in category at different treatment time are not significantly different $(P>0.05)$.

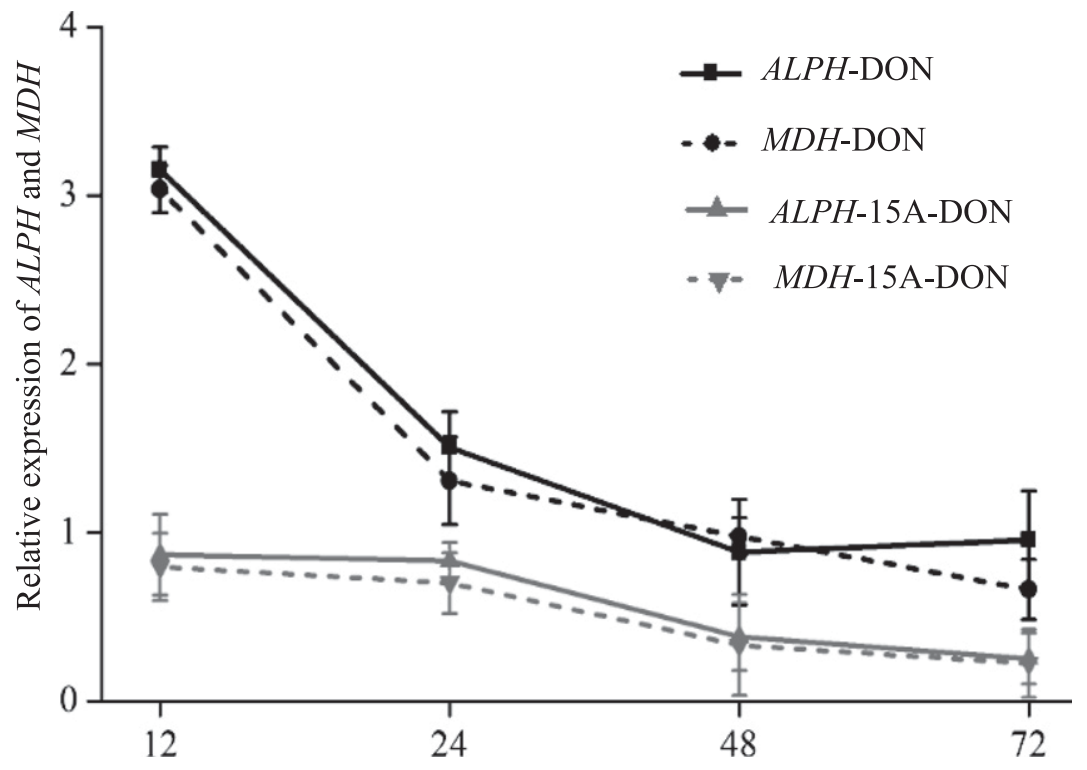

Treatment time (h)

Fig. 7. Effect of deoxynivalenol (DON) and 15-acetyl-deoxynivalenol (15-ADON) on dehydrogenase of maize seedling root. 
and unfortunately the latter appeared to be more toxic to wheat (Alexander et al. 2011; Desjardins 2006). F. graminearum isolates are 15-ADON producers in the northern region of China, including north of the Yangtze River and the northeastern region, but both 15-ADON and 3-ADON producers were detected in the south, such as Henan Province (Wang et al. 2010; Yang et al. 2008). There is no document of chemotypes of $F$. graminearum in the Hexi Corridor before this study. In the current study, all 23 isolates of $F$. graminearum from the Hexi Corridor belonged to the 15-ADON genotype, and they just produced DON and 15-ADON, which indicated the main chemotype of $F$. graminearum in Zhangye is $15-\mathrm{ADON}$.

We have demonstrated that the total content of 15-ADON and DON from rice media of $F$. graminearum were not consistently associated with the level of virulence of the isolates, but they showed positive correlation at 6 and 12 dpi respectively in inoculated maize roots. This is because many factors can affect mycotoxin production. For example, environmental factors are implicated in the regulation of DON production, including polyamines, lower $\mathrm{pH}$, and oxidative stress (Jiang et al. 2015; Ponts et al. 2007; Walter et al. 2010). Reactive oxygen species (ROS) can regulate DON synthesis in $F$. graminearum (Audenaert et al. 2010). Because oxidative burst is a common plant defense response, $F$. graminearum may use the host-generated ROS as a trigger to upregulate DON biosynthesis (Jiang et al. 2015).
Aldehydes are generated in response to a suite of environmental stresses. $A L D H$ comprises a group of genes of related enzymes that metabolize endogenous and exogenous aldehydes (An et al. 2014; Zhou et al. 2012). The ALDH9 gene is involved in drought stress, acid tolerance, and pathogen infection in maize (Zhou et al. 2012). $M D H$ produces a key enzyme in malate metabolism involved in plant development, nutrient uptake, and oxidative stress (Hadži-Tašković et al. 2011; Menckhoff et al. 2013). In this study, both DON and 15-ADON upregulated the expression of $A L D H$ and $M D H$, and 15ADON showed a greater effect than DON. Dehydrogenase activity also reflects the root vitality. Root vitality was highly correlated with the expression of $A L D H 9$ and $M D H$, when treated with the two mycotoxins.

Multilamellar bodies have been reported in many diseases of human and animals (Satoh et al. 1997; Shapiro Stanley and Klavins 1993), and observed in various cells such as degeneration of nerves and brain, regeneration of nerves, and wound healing (Schmitz and Müller 1991). Some drugs with cationic amphiphilic structure can induce multilamellar bodies. Multilamellar bodies are involved in storage of proteins and lipids, as well as secretion of lipids to the cell surface. The functions and origin of multilamellar bodies in plant cells are not clear. They are present in the cytoplasm, at the interface of cytoplasm and vacuole, and inside vacuoles, which suggests that
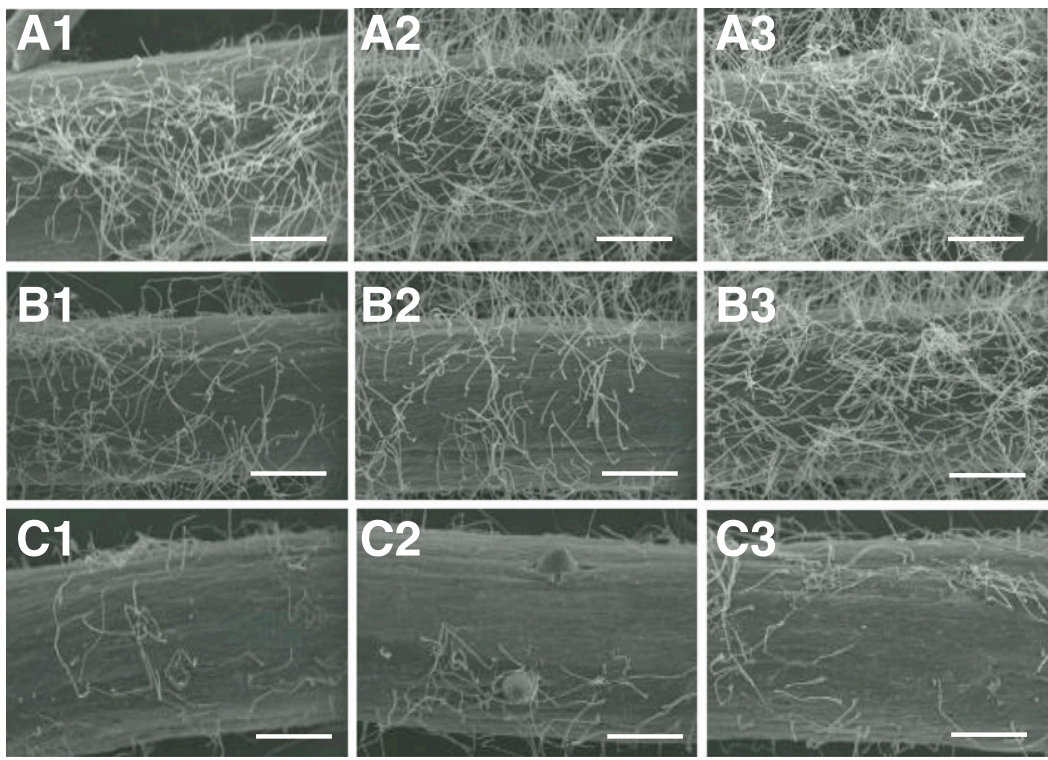

Fig. 8. Effect of deoxynivalenol (DON) and 15-acetyl-deoxynivalenol (15-ADON) on root hair development (SEM). Root hairs were observed after root treating by water (A), DON (B), and 15-ADON (C) for $24 \mathrm{~h}(1), 48 \mathrm{~h}(2)$, and $72 \mathrm{~h}$ (3). Root hairs treated by DON (B1, B2) were sparser than that of control (A1, A2) at $24 \mathrm{~h}$ and $48 \mathrm{~h}$, but no obvious differences were observed at $72 \mathrm{~h}$ (A3, B3). For the 15-ADON treatment, root hairs were inhibited at all times (C1, C2, and C3). Bars $=500 \mu \mathrm{m}$.
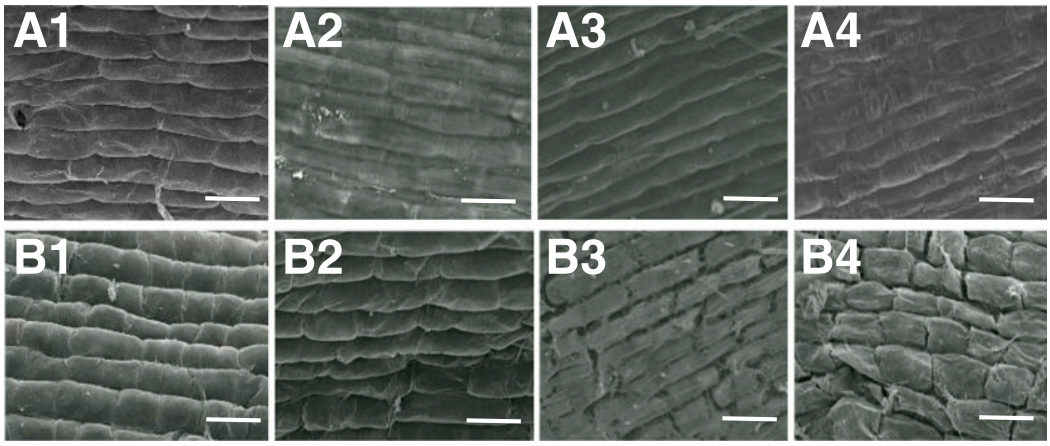

Fig. 9. Effects of deoxynivalenol (DON) and 15-acetyl-deoxynivalenol (15-ADON) on the structure of root tips, which were observed by SEM after DON (A) and 15-ADON (B) treatments for $24 \mathrm{~h}(1), 48 \mathrm{~h}(2), 72 \mathrm{~h}(3)$, and $96 \mathrm{~h}(4)$. Bars $=50 \mu \mathrm{m}$. 
they are transported from the cytoplasm to the vacuole (Papini and van Doorn 2016).

Large amounts of lipid droplets were also observed in maize roots treated by DON in this study. Lipid droplets are the intracellular organelle specialized in assembling, storing, and supplying lipids (Pol et al. 2014). Lipid droplets are involved in processes like stress response, pathogen resistance, and hormone metabolism. Lipid droplets in plants develop at distinct locations or subdomains of the endoplasmic reticulum. Some key enzymes are responsible for the biosynthesis of structural proteins that stabilize and localize lipid droplets within discrete regions of endoplasmic reticulum (Chapman et al. 2012). In this study, multilamellar bodies of endoplasmic reticulum are accompanied by abundant lipid droplets in DON-treated roots. We speculated that DON induces multilamellar bodies of endoplasmic reticulum to excrete lipid containing proteins related to plant defense responses to relieve the effect of DON on maize root tips.

Trichothecenes act as virulence factors to enhance the spread of $F$. graminearum on crops, but the importance of their production varies depending on the host (Gu et al. 2010). There were positive correlations among disease incidence, fungal biomass, and mycotoxins in Fusarium head blight (Sugita-Konsihi et al. 2006). In the current study, DON dominated at 6 dpi with slight symptoms, whereas 15-ADON dominated at 12 dpi with significant symptoms. In addition, the highly virulent isolates were associated with a greater biomass of $F$. graminearum. Thus, both mycotoxin synthesis and increased mycelial development are associated with virulence.

Both DON and 15-ADON are toxic to mammals, but their toxic effects may vary depending on the test organism. The acute toxic effect of $15-\mathrm{ADON}$ was very similar to that of DON in swine, but different in mouse (Forsell et al. 1987; Pestka et al. 1987). On intestinal epithelial cells, DON was less toxic than 15-ADON, which impaired the barrier function of cells and caused more histological lesions (Pinton et al. 2012). We have demonstrated in this study that DON and 15-ADON function differently on plants. DON affected the function of cell organelles by changing their number and shape, whereas 15-ADON destroyed cell organelles and killed cells directly. Therefore, 15-ADON is more toxic to cells of root tips than DON. 15-ADON may be associated with reduced root development. Spores or hyphae of $F$. graminearum carried by maize seed or residues infect young radicals after seed germination and produces a large quantity of $15-\mathrm{ADON}$, which decreases root vitality, promotes $F$. graminearum expansion, destroys the cells of root tips, inhibits the development of radicals and root hairs, and leads to insufficient nutrients and water for seedling growth. It is likely both mycotoxins contribute to MSB symptoms, such as necrosis and root rot, but the role of 15-ADON may have been underestimated as most of
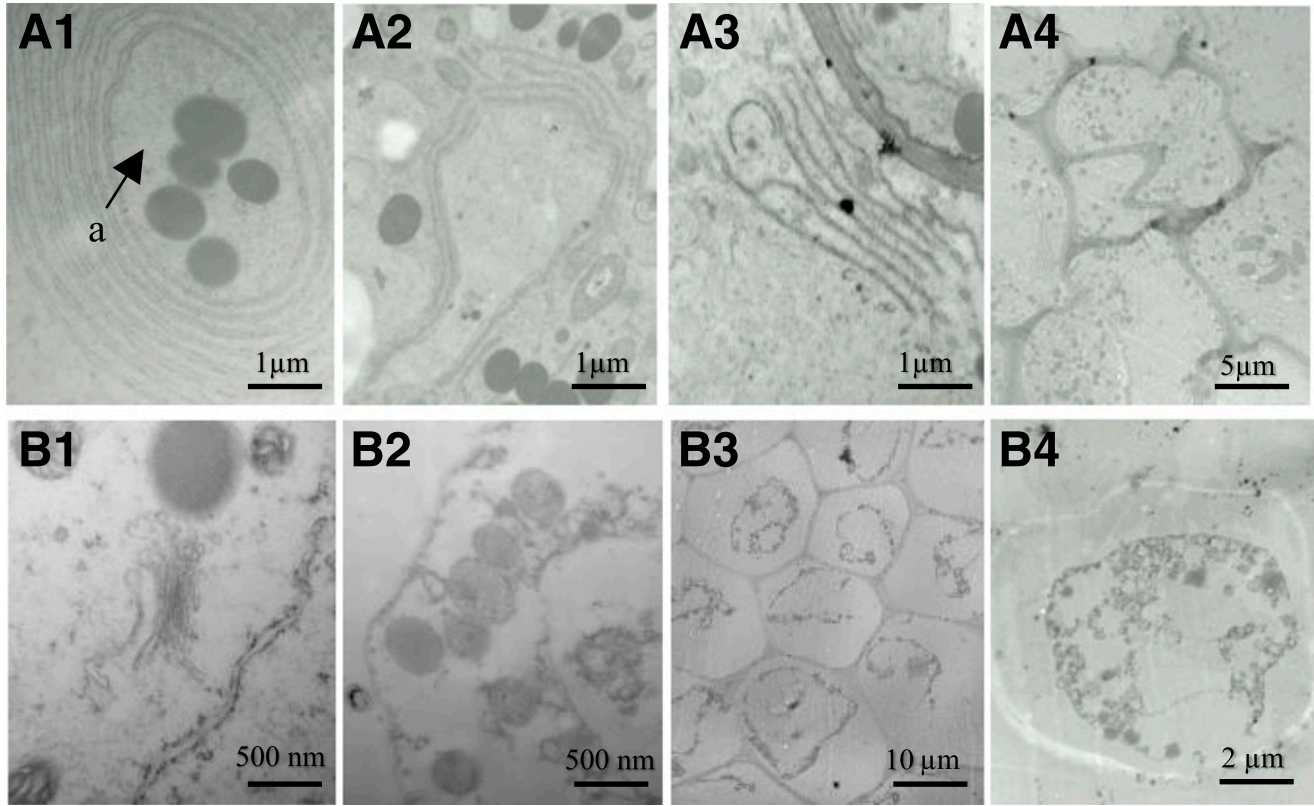

Fig. 10. Effects of deoxynivalenol (DON) and 15-acetyl-deoxynivalenol (15-ADON) on cells of root tips, which were observed by TEM after DON (A) and 15-ADON (B) treatment for $24 \mathrm{~h}(1), 48 \mathrm{~h}(2), 72 \mathrm{~h}(3)$, and $96 \mathrm{~h}$ (4). Concentric membranous bodies (CMB) were found in cells of $24 \mathrm{~h}$ DON treatment (A1), lipid drops (a) were enclosed in CMBs. They were broken at $48 \mathrm{~h}$ (A2), then cracked into small multilevel parallel endoplasmic reticulum segments at $72 \mathrm{~h} \mathrm{(A3);} \mathrm{intact} \mathrm{cells} \mathrm{were} \mathrm{observed} \mathrm{after} 96 \mathrm{~h}$ DON treatment (A4). For 15-ADON treatment, cell organelles were clearly visible at $24 \mathrm{~h}$ (B1) but became fuzzy at $48 \mathrm{~h}$ (B2); plasmolysis was observed in most cells at $72 \mathrm{~h}$ (B3) and cytomembrane was broken at $96 \mathrm{~h}(\mathrm{~B} 4)$.
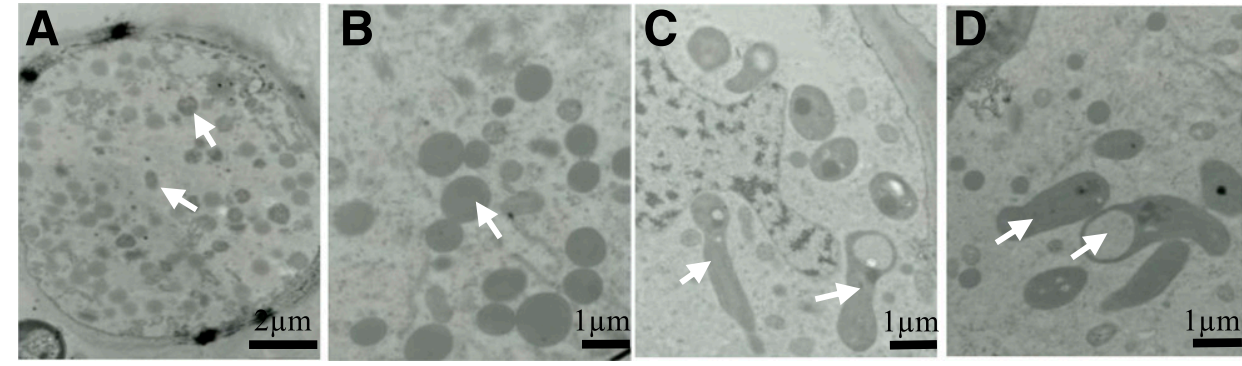

Fig. 11. TEM images of lipid droplets in root tip cells of maize seedling treated by deoxynivalenol (DON). A large number of lipid droplets (arrow) were observed at $24 \mathrm{~h}(\mathrm{~A})$ and $48 \mathrm{~h}$ (B) with DON treatments; the number decreased at $72 \mathrm{~h}$ (C) and $96 \mathrm{~h}$ (D) but part of them showed abnormal shapes. 
the reports have focused on DON (Audenaert et al. 2013; Bai et al. 2002; Proctor et al. 1995; Walter et al. 2010). The function of 15-ADON in MSB caused by $F$. graminearum should be further studied.

\section{Acknowledgments}

This research was partly supported by CSC grant (no. 201506350039) and SHC-CAU International Cooperation Project (no. 201501). We are grateful to the Seed Pathology and Fungicide Pharmacology team in China Agricultural University for their technical assistance and their advice.

\section{Literature Cited}

Alexander, N. J., McCormick, S. P., Waalwijk, C., Van Der Lee, T., and Proctor, R. H. 2011. The genetic basis for 3-ADON and 15-ADON trichothecene chemotypes in Fusarium. Fungal Genet. Biol. 48:485-495.

An, X., Duan, F. Y., Guo, S., Chen, F. J., Yuan, L. X., and Gu, R. L. 2014. Transcriptional regulation of expression of the maize aldehyde dehydrogenase 7 gene (ZmALDH7B6) in response to abiotic stresses. J. Integr. Agric. 13:1900-1908.

Arif, M., Pani, D. R., Zaidi, N. W., and Singh, U. S. 2011. PCR-based identification and characterization of Fusarium sp. associated with mango malformation. Biotechnol. Res. Int. 2011:141649.

Audenaert, K., Callewaert, E., Höfte, M., De Saeger, S., and Haesaert, G. 2010. Hydrogen peroxide induced by the fungicide prothioconazole triggers deoxynivalenol (DON) production by Fusarium graminearum. BMC Microbiol. 10:112

Audenaert, K., Vanheule, A., Höfte, M., and Haesaert, G. 2013. Deoxynivalenol: a major player in the multifaceted response of Fusarium to its environment. Toxins (Basel) 6:1-19.

Bai, G. H., Desjardins, A. E., and Plattner, R. D. 2002. Deoxynivalenolnonproducing Fusarium graminearum causes initial infection, but does not cause disease spread in wheat spikes. Mycopathologia 153:91-98.

Bruns, T. 2015. The role of Fusarium mycotoxins in seedling infection of soybeans, wheat and maize. Iowa State University, Ames, IA.

Bushnell, W. R., Seeland, T. M., Perkins-Veazie, P., Krueger, D. E., Collins, J., Russo, V. M., and Wolpert, T. 2005. The effects of deoxynivalenol on barley leaf tissues. Pages 270-284 in: Genomic and Genetic Analysis of Plant Parasitism and Defense. Proceedings of the 9th Japan-US Science Seminar on Plant-Pathogen Interactions, Shizuoka, Japan, 2-7 November 2003. APS Press, St. Paul, MN

Chapman, K. D., Dyer, J. M., and Mullen, R. T. 2012. Biogenesis and functions of lipid droplets in plants Thematic Review Series: Lipid Droplet Synthesis and Metabolism: from Yeast to Man. J. Lipid Res. 53:215-226.

Clemensson-Lindell, A. 1994. Triphenyltetrazolium chloride as an indicator of fine-root vitality and environmental stress in coniferous forest stands: applications and limitations. Plant Soil 159:297-300.

Covarelli, L., Beccari, G., Steed, A., and Nicholson, P. 2012. Colonization of soft wheat following infection of the stem base by Fusarium culmorum and translocation of deoxynivalenol to the head. Plant Pathol. 61:1121-1129.

Desjardins, A. E. 2006. Fusarium Mycotoxins: Chemistry, Genetics, and Biology. APS Press, St. Paul, MN.

du Toit, L. J., Kirby, H. W., and Pedersen, W. L. 1997. Evaluation of an aeroponics system to screen maize genotypes for resistance to Fusarium graminearum seedling blight. Plant Dis. 81:175-179.

Eudes, F., Comeau, A., Rioux, S., and Collin, J. 2000. Toxic effects of deoxynivalenol on ribosomes and tissues of the spring wheat cultivars frontana and casavant. Can. J. Plant Pathol. 22:286-292.

Forsell, J. H., Jensen, R., Tai, J. H., Witt, M., Lin, W. S., and Pestka, J. J. 1987. Comparison of acute toxicities of deoxynivalenol (vomitoxin) and 15acetyldeoxynivalenol in the B6C3F 1 mouse. Food Chem. Toxicol. 25:155-162.

Gu, R., Fu, J., Guo, S., Duan, F., Wang, Z., Mi, G., and Yuan, L. 2010. Comparative expression and phylogenetic analysis of maize cytokinin dehydrogenase/ oxidase (CKX) gene family. J. Plant Growth Regul. 29:428-440.

Guan, M., Wang, Y., Xie, L., Ruan, J., and Chen, B. 1994. Fungus pathogen identification and control of maize seedling blight. Acta Agric. Zhejiangensis 6:18-21

Guo, X. W., Fernando, W. G. D., and Seow-Brock, H. Y. 2008. Population structure, chemotype diversity, and potential chemotype shifting of Fusarium graminearum in wheat fields of Manitoba. Plant Dis. 92:756-762.

Hadži-Tašković, S. V., Vuletić, M., Marković, K., and Vučinić, Z. 2011. Cell wallassociated malate dehydrogenase activity from maize roots. Plant Sci. 181: 465-470.

Hellin, P., Scauflaire, J., Van Hese, V., Munaut, F., and Legrève, A. 2016. Sensitivity of Fusarium culmorum to triazoles: impact of trichothecene chemotypes, oxidative stress response and genetic diversity. Pest Manag. Sci. (in press) doi:10.1002/ps.4450

Islam, E., Yang, X., Li, T., Liu, D., Jin, X., and Meng, F. 2007. Effect of Pb toxicity on root morphology, physiology and ultrastructure in the two ecotypes of Elsholtzia argyi. J. Hazard. Mater. 147:806-816.

Jiang, C., Zhang, S., Zhang, Q., Tao, Y., Wang, C., and Xu, J. R. 2015. FgSKN7 and FgATF1 have overlapping functions in ascosporogenesis, pathogenesis and stress responses in Fusarium graminearum. Environ. Microbiol. 17:1245-1260.

Kimura, M., Kaneko, I., Komiyama, M., Takatsuki, A., Koshino, H., Yoneyama, K., and Yamaguchi, I. 1998. Trichothecene 3-O-acetyltransferase protects both the producing organism and transformed yeast from related mycotoxins cloning and characterization of Tri101. J. Biol. Chem. 273:1654-1661.

Kingsland, G., and Wernham, C. 1960. Variation in maize seedling blight symptoms with changes in pathogen species, isolate, and host genotype. Plant Dis. Report. 44:496-497.

Lei, Y., and Chen, L. 2006. Studies on the occurrence law and control techniques of maize seedling wilt disease in hexi corridor. J. Maize Sci. 14:151-154.

Liang, J. M., Xayamongkhon, H., Broz, K., Dong, Y., McCormick, S. P., Abramova, S., Ward, T. J., Ma, Z. H., and Kistler, H. C. 2014. Temporal dynamics and population genetic structure of Fusarium graminearum in the upper Midwestern United States. Fungal Genet. Biol. 73:83-92.

Livak, K. J., and Schmittgen, T. D. 2001. Analysis of relative gene expression data using real-time quantitative PCR and the $2^{-\Delta \Delta C \mathrm{~T}}$ method. Methods 25:402-408.

Menckhoff, L., Mielke-Ehret, N., Buck, F., Vuletić, M., and Lüthje, S. 2013. Plasma membrane-associated malate dehydrogenase of maize (Zea mays L.) roots: Native versus recombinant protein. J. Proteomics 80:66-77.

Miller, J. D., and Ewen, M. A. 1997. Toxic effects of deoxynivalenol on ribosomes and tissues of the spring wheat cultivars Frontana and Casavant. Nat. Toxins 5:234-237.

Mudge, A. M., Dill-Macky, R., Dong, Y., Gardiner, D. M., White, R. G., and Manners, J. M. 2006. A role for the mycotoxin deoxynivalenol in stem colonisation during crown rot disease of wheat caused by Fusarium graminearum and Fusarium pseudograminearum. Physiol. Mol. Plant Pathol. 69:73-85.

Munkvold, G. P., and O'Mara, J. K. 2002. Laboratory and growth chamber evaluation of fungicidal seed treatments for maize seedling blight caused by Fusarium species. Plant Dis. 86:143-150.

Obanor, F., and Chakraborty, S. 2014. Aetiology and toxigenicity of Fusarium graminearum and $F$. pseudograminearum causing crown rot and head blight in Australia under natural and artificial infection. Plant Pathol. 63:1218-1229.

Okiyoneda, T., Harada, K., Takeya, M., Yamahira, K., Wada, I., Shuto, T., and Kai, H. 2004. $\Delta$ F508 CFTR pool in the endoplasmic reticulum is increased by calnexin overexpression. Mol. Biol. Cell 15:563-574

Oliveira, P. M., Mauch, A., Jacob, F., Waters, D. M., and Arendt, E. K. 2012 Fundamental study on the influence of Fusarium infection on quality and ultrastructure of barley malt. Int. J. Food Microbiol. 156:32-43.

Papini, A., and van Doorn, W. G. 2016. Plastid degeneration in Tillandsia (Bromeliaceae) provides evidence about the origin of multilamellar bodies in plants. bioRxiv (online) doi:10.1101/038158

Pestka, J. J., Lin, W. S., and Miller, E. R. 1987. Emetic activity of the trichothecene 15-acetyldeoxynivalenol in swine. Food Chem. Toxicol. 25:855-858.

Pinton, P., Tsybulskyy, D., Lucioli, J., Laffitte, J., Callu, P., Lyazhri, F., Grosjean, F. I. P., Bracarense, A. P., Clauw, M. K., and Oswald, I. P. 2012. Toxicity of deoxynivalenol and its acetylated derivatives on the intestine: differential effects on morphology, barrier function, tight junctions proteins and MAPKinases. Toxicol. Sci. 130:180-190.

Pol, A., Gross, S. P., and Parton, R. G. 2014. Biogenesis of the multifunctional lipid droplet: Lipids, proteins, and sites. J. Cell Biol. 204:635-646.

Ponts, N., Pinson-Gadais, L., Barreau, C., Richard-Forget, F., and Ouellet, T. 2007. Exogenous $\mathrm{H} 2 \mathrm{O} 2$ and catalase treatments interfere with Tri genes expression in liquid cultures of Fusarium graminearum. FEBS Lett. 581:443-447.

Proctor, R. H., Hohn, T. M., and McCormick, S. P. 1995. Reduced virulence of Gibberella zeae caused by disruption of a trichthecine toxin biosynthetic gene. Mol. Plant Microbe Interact. 8:593-601.

Quarta, A., Mita, G., Haidukowski, M., Logrieco, A., Mulè, G., and Visconti, A 2006. Multiplex PCR assay for the identification of nivalenol, 3- and 15-acetyldeoxynivalenol chemotypes in Fusarium. FEMS Microbiol. Lett. 259:7-13.

Quarta, A., Mita, G., Haidukowski, M., Santino, A., Mulè, G., and Visconti, A. 2005. Assessment of trichothecene chemotypes of Fusarium culmorum occurring in Europe. Food Addit. Contam. 22:309-315

Quesada-Ocampo, L. M., Al-Haddad, J., Scruggs, A. C., Buell, C. R., and Trail, F. 2016. Susceptibility of maize to stalk rot caused by Fusarium graminearum deoxynivalenol and zearalenone mutants. Phytopathology 106:920-927.

Reynoso, M. M., Ramirez, M. L., Torres, A. M., and Chulze, S. N. 2011 Trichothecene genotypes and chemotypes in Fusarium graminearum strains isolated from wheat in Argentina. Int. J. Food Microbiol. 145:444-448.

Satoh, A., Tokunaga, F., Kawamura, S., and Ozaki, K. 1997. In situ inhibition of vesicle transport and protein processing in the dominant negative Rab1 mutant of Drosophila. J. Cell Sci. 110:2943-2953.

Schmitz, G., and Müller, G. 1991. Structure and function of lamellar bodies, lipidprotein complexes involved in storage and secretion of cellular lipids. J. Lipid Res. 32:1539-1570.

Shapiro Stanley, H., and Klavins, J. V. 1993. Teaching case concentric membranous bodies and giant mitochondria in hepatocytes from a patient with AIDS. Ultrastruct. Pathol. 17:557-563.

Stephens, A. E., Gardiner, D. M., White, R. G., Munn, A. L., and Manners, J. M 2008. Phases of infection and gene expression of Fusarium graminearum during crown rot disease of wheat. Mol. Plant Microbe Interact. 21:1571-1581.

Sugita-Konsihi, Y., Tanaka, T., Tabata, S., Nakajima, M., Nouno, M., Nakaie, Y., Chonan, T., Aoyagi, M., Kibune, N., Mizuno, K., Ishikuro, E., Kanamaru, N., Minamisawa, M., Aita, N., Kushiro, M., Tanaka, K., and Takatori, K. 2006. Validation of an HPLC analytical method coupled to a multifunctional clean-up column for the determination of deoxynivalenol. Mycopathologia 161:239-243.

Walter, S., Nicholson, P., and Doohan, F. M. 2010. Action and reaction of host and pathogen during Fusarium head blight disease. New Phytol. 185:54-66. 
Wang, G., Yin, W., Jin, J., and Yin, W. 1992. Investigation of pathogenic factors of maize seedling blight. Plant Prot. 18:23-24.

Wang, L., Xu, X., and Chen, J. 2012. Population and distribution of pathogenic fungi of maize seedling blight in the Northeast area of China. China Plant Prot. 31:48-51.

Wang, X., Cui, Y., Fan, F., Song, Y., Ren, J., Meng, Q., Xu, W., and Jiang, L. 2010. Phylogenetic, Carbendazim sensitivity and mycotoxin genotype analyses of Fusarium graminearum complex species isolated from wheat Fusarium head blight in China. J. Phytopathol. 158:576-578.

Winter, M., Koopmann, B., Döll, K., Karlovsky, P., Kropf, U., Schlüter, K., and von Tiedemann, A. 2013. Mechanisms regulating grain contamination with trichothecenes translocated from the stem base of wheat (Triticum aestivum) infected with Fusarium culmorum. Phytopathology 103:682-689.

Xin, H., Ma, J., and Mao, T. 2010. Screening fungicides for controlling maize seedling blight. Chin. Agric. Sci. Bull. 26:319-322.
Xu, L., Zhang, G., Guo, C., Zhang, Y., Zhang, Y., Zheng, J., and Fang, B. 2014 Simultaneous determination of major type-B trichothecenes and the de-epoxy metabolite of deoxynivalenol in chicken tissues by HPLC-MS/MS. J. Sep. Sci. 37:642-649.

Yang, L., van der Lee, T., Yang, X., Yu, D., and Waalwijk, C. 2008. Fusarium Populations on Chinese barley show a dramatic gradient in mycotoxin profiles. Phytopathology 98:719-727.

Zhang, L., Jia, X., Chen, C., and Zhou, M. 2013. Characterization of carbendazim sensitivity and trichothecene chemotypes of Fusarium graminearum in Jiangsu Province of China. Physiol. Mol. Plant Pathol. 84:53-60.

Zhao, P., and Ren, A. 2003. Status and Control of Maize Seedling Blight in Liaocheng Region. Rain Fed Crops 23:47-48.

Zhou, M., Zhang, Q., Zhou, M., Qi, L., Yang, X., Zhang, K., Pang, J., Zhu, X., Shao, J., Tang, Y., and $\mathrm{Wu}, \mathrm{Y}$. 2012. Aldehyde dehydrogenase protein superfamily in maize. Funct. Integr. Genomics 12:683-691. 